\title{
Radiosensitization Effects of a Zataria multiflora Extract on Human Glioblastoma Cells
}

\author{
Azar Aghamohammadi ${ }^{1,2}$, Seyed Jalal Hosseinimehr ${ }^{1,2 *}$, Arash Ghasemi ${ }^{3}$, \\ Mohammad Azadbakht ${ }^{1}$, Tayyeb Allahverdi Pourfallah ${ }^{4}$
}

\begin{abstract}
Background: Although radiotherapy is one of the most effective strategies in the treatment of cancers, it is associated with short and long term side effects on normal tissues. Zataria multiflora Boiss (Laminacea) (ZM) has several biological properties such as antioxidant and anti-inflammation activities.Here we investigated cell killing effects of a hydroalcoholic Zataria multiflora extract on cell death induced by ionizing radiation in a human glioblastoma cell line (A172) and human non-malignant fibroblasts (HFFF2) in vitro. Materials and Methods: A172 and HFFF2 cells were treated with a hydroalcoholic extract of dried aerial parts of Zataria multiflora at different concentrations $(25,50,100,150$ and $200 \mu \mathrm{g} / \mathrm{ml})$ and then exposed to ionizing radiation (IR). Cell proliferation and DNA fragmentation were evaluated. Thymol content in the extract was analyzed and quantified by HPLC methods. Results: A172 cell proliferation was significantly inhibited by $Z M$. The percentage cell survival was 91.8 \pm 8.57 for cells treated with $200 \mu \mathrm{g} / \mathrm{ml}$ of $Z M$ extract alone while it was $76.0 \pm 4.27$ and $66.2 \pm 8.42$ for cells treated with $Z M$ and exposed to IR at doses of 3Gy and 6Gy, respectively. Radiation-induced apoptosis in A172 cells was significantly increased following treatment with $Z M$ at doses of $200 \mu \mathrm{g} / \mathrm{ml}$. $Z M$ extract did not exhibit any enhanced cell killing effects and apoptosis caused by IR on HFFF2 cells. Conclusions: These data show selective radiosensitization effects of $Z M$ in $\mathbf{A 1 7 2}$ cells apparently due to increased radiation-induced apoptosis.
\end{abstract}

Keywords: Ionizing radiation - Zataria multiflora - anti-proliferation - apoptosis - radiosensitive

Asian Pac J Cancer Prev, 16 (16), 7285-7290

\section{Introduction}

Ionizing radiation widely is used for the treatment of cancers. Although radiotherapy (RT) is one of the most effective strategies for treatment of cancers (Szostak and Kyprianou, 2000), it is associated with some side effects on normal tissues. Side effects are uncomfortable and can be a limiting factor in cancer treatment planning (Park et al., 2014). Both of normal and cancer cells are damaged by radiation but cancer cells cannot repair themselves as well as normal cells. Normal cells can keep their normal function sooner than cancer cells (Baskar et al., 2012). The therapeutic effect of RT in cancer patients depends on tumor radiosensitivity and the tolerance of normal tissues (Park et al., 2014). The efficacy of all anticancer treatments is reduced by the presence of cells displaying changes in their apoptotic system (Vogelstein and Kinzler, 2004). Selective induction of apoptosis in cancer cells is a main therapeutic approach in radiation oncology. However, the therapeutic efficacy of RT as a major modality for human cancer treatment is often limited because of RT-resistance in many cancers (Chakravarti and Palanichamy, 2008).
Hence, it is interest to find an agent to protect normal tissues from ionizing radiation without reduction of RT effectiveness in cancer cells (Sebastia et al., 2013). Many synthetic agents have been investigated recently but they have many problems such as high cost, complication and toxicity. The study of natural products has been one of the most successful strategies for discovery of new medicines and nowadays, interest has been attended in natural products which have lower complication than synthetic agents (Maurya et al., 2006; Sebastia et al., 2013). Herbal based compounds are capable to modify radiation effects on normal cells (Lachumy et al., 2013; Kma, 2014). Herbal extracts were reported to have radiosensitive effects which have increase cell killing effect of ionizing radiation on cancer cell (Yao et al., 2014). In addition, some natural products were protected normal cell against toxicity induced by ionizing radiation (Wang et al., 2014; Xu et al., 2014).

The Lamianceae family is one of the largest herbal families growing in the world andhas 200 genus and 20005000 species. Zataria multiflora Boiss. (ZM) (syn:Zataria bracteata Boiss. Zataria multiflora var. elatior Boiss)

${ }^{1}$ Traditional and Complementary Medicine Research Center, ${ }^{2}$ Department of Radiopharmacy, Faculty of Pharmacy, ${ }^{3}$ Department of Radiology and Radiation Oncology, ${ }^{4}$ Department of Biochemistry and Biophysics, Faculty of Medicine, Mazandaran University of Medical Sciences, Sari, Iran*For correspondence: sjhosseinim@yahoo.com, sjhosseinim@mazums.ac.ir 
is a thyme-like plant is a member of this family with multiple, thin, hard, and forked stalks. (Hosseinzadeh et al., 2000; Alizadeh et al., 2009). It has chemical and pharmacological similarities to Thymus vulgaris, the wellknown and widely investigated medicinal plant. Zataria contains thymol, carvacrol, zatrinal, oleanolicacid, betulic acid, rosmarinic acid and monoterpenoids, sesquiterpenoids, p-cymene, y-terpinene (Alizadeh et al., 2009). The main components of $Z M$ oil are phenolic compounds and the biological effects of $Z M$ are mainly phenolic compounds, especially thymol and carvacrol (Figure 1) (Mahboubi and Bidgoli, 2010).

$Z M$ recognized with important medicinal activities, including antifungal (Saei-Dehkordi et al., 2010), antierythma (Amanlou et al., 2006), antinociceptive (Ramezani et al., 2004), antioxidative stress (Sharififar et al., 2007; Kavoosi et al., 2012) antimicrobial (Alizadeh et al., 2009) spasmolytic, anti-inflammatory (Sajed et al., 2013) immunostimulant (Shokri et al., 2006), pain relieving (Jaffary et al., 2004) and radioprotective effects (Hosseinimehr et al., 2011). Glioblastoma multiflorme is most aggressive primary brain tumor. Apoptosis induced by ionizing radiation in human glioblastoma cell line (A172) (Yao et al., 2003) and human non-malignant fibroblast cells (HFFF2) (Antoccia et al., 2009) were evaluated in previous studies. In this study, HFFF2 was used as a model of non-malignant cell line for comparison with malignant cell as A172. The aim of this study was to investigate cell killing effect of $Z M$ extract on cell death induced by ionizing radiation (IR) in (A172) and (HFFF2) in vitro.

\section{Materials and Methods}

\section{Chemicals}

Roswell Park Memorial Institute (RPMI) medium, ethanol, fetal bovine serum (FBS), penicillin, trypsin with EDTA, DMEM (Dulbecco's modified eagle's medium) medium and streptomycinwere from Gibco (Paisley, UK). Glutaraldehyde, propidium iodide (PI), thiazolyl blue tetrazolium bromide (MTT) and phosphate buffered saline (PBS) were from Sigma (USA). Dimethyl sulfoxide (DMSO), thymol, carvacrol, acetonitrile, methanol, and acetic acid were purchased from Merck (Germany). Plastic

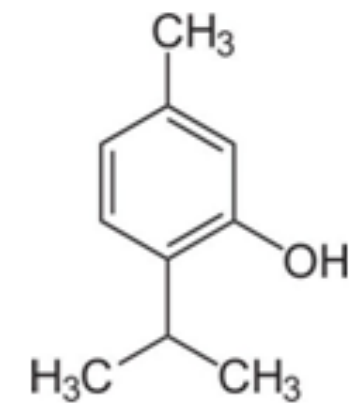

Thymol

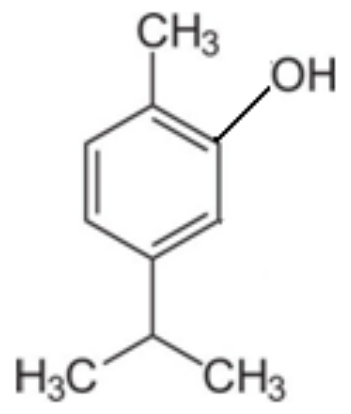

Carvacrol
Figure 1. Chemical Structures of Thymol and Carvacrol disposable 96-well tissue culture dishes, 12-welltissue culture dishes, pipettes and tubes were purchased from Nest (China).

\section{Plant material}

The dried aerial parts of Zataria multiflora were collected from their major growing areas around Firozabad city of Fars province GO $\left(28.8194258^{\circ} \mathrm{N}, 52.5518705^{\circ}\right.$ W), Iran at the full flowering stage (June and July 2012). It was confirmed by a senior botanist Prof. Mohammad Azadbakht atthe Mazandaran University of Medical Science, Iran (Herbarium number: F-1-8-4-21). Five gram of the homogenous powder (1 $\mathrm{mm}$ in diameter mesh No. 18) was mixed with $50 \mathrm{ml}$ hydroalcholic solvent with ethanol $70 \%$ for $48 \mathrm{~h}$. The solution was filtered through filter paper, and then solvent was evaporated and residue was freeze dried.

\section{HPLC analysis}

The HPLC system consists of a model K-1001 solvent delivery system equipped with a Rheodyne injection valve ( $20 \mu \mathrm{l}$ sample loop inserted) and a UV-Vis spectrophotometer detector model K-2600 set at $274 \mathrm{~nm}$ (all from Knauer Assoc., Germany). HPLC analyze was performed using an ODS-C18 column $(150 \times 4.6 \mathrm{~mm}$ i.d., $5 \mu \mathrm{m}$ particle size), and the corresponding guard column. Mobile phase was a mixture of acetonirile, water and acetic acid. All solvents were filtered and degassed earlier entering the column.

\section{Culture of cancer cells}

Human glioblastoma cell line (A172) and human Caucasian fetal foreskin fibroblast (HFFF2) was purchased from the Pasture Institute of Iran. A172 and HFFF2 were cultured in RPMI and DMEM containing $10 \%$ fetal bovine serum and $100 \mu \mathrm{g} / \mathrm{mL}$ penicillin-streptomycin. Cells were incubated at $37^{\circ} \mathrm{C}$ in a humidified atmosphere $\left(5 \% \mathrm{CO}_{2}\right)$.

\section{Irradiation}

Cells were irradiated with $6 \mathrm{MeV}$ electron beam produced by a radiotherapy machine (Linear accelerator, Siemens, Primus, Germany) at a $1.27 \mathrm{~Gy} / \mathrm{min}$ dose rate and source to sample distance (SSD) of $100 \mathrm{~cm}$. Doses of irradiation were $3 \mathrm{~Gy}$ and 6Gy. For each dose, control cells were simultaneously exposed to sham radiation. Radiation doses and the concentrations of $Z M$ for each assay were determined by prior optimization.

\section{Antiproliferation Assay}

A172 and HFFF2 cells $(20,000$ cells $)$ were plated in each well of a 96-well plate and add $200 \mu \mathrm{l}$ medium and were incubated and allowed to attach for $48 \mathrm{~h}$ in a humidified atmosphere of $5 \% \mathrm{CO}_{2}$ in air at $37^{\circ} \mathrm{C}$ (Incubator-Biotek-NB 203L Korea). After incubation, cells were treated with various concentrations of $Z M(25$, $50,100,150$ and $200 \mu \mathrm{g} / \mathrm{ml})$ and incubated for $2 \mathrm{~h}$ before radiation. In this study, a separate group with IR alone, without $Z M$ extract, as well as separate groups with $Z M$ extract alone, without IR, at these concentrations was used for comparison between groups. $Z M$ was dissolved in ethanol and diluted with medium. After radiation, the 
culture medium was carefully removed and exchanged for a fresh medium. The cells were incubated for $48 \mathrm{~h}$ in a humidified atmosphere of $5 \% \mathrm{CO}_{2}$ in air at $37^{\circ} \mathrm{C}$. After $48 \mathrm{~h}$, the culture medium was removed and MTT solution $(5 \mathrm{mg} / \mathrm{ml} \mathrm{PBS}$ ) was then added and the plate was located in optimal atmosphere at $37^{\circ} \mathrm{C}$. The metabolically active cells reduced MTT to blue formazan crystals. After incubating for $4 \mathrm{~h}$, the formazan crystals in each well were dissolved in DMSO. The absorbance of each well was read on an ELISA Reader (Bioteck, USA). Cells without any treatment were used as control for comparison of absorbance and cell survival.

Fluorescence microscopic observation of apoptotic cells A172 and HFFF2 cells $(100,000)$ were plated in each well of a 12-well plate and add $1 \mathrm{ml}$

medium and were incubated and allowed to attach for $48 \mathrm{~h}$ in a humidified atmosphere of $5 \%$

$\mathrm{CO}_{2}$ in air at $37^{\circ} \mathrm{C}$. After Incubation, cells were treated with various concentrations of $Z M$ extract (100 and $200 \mu \mathrm{g} / \mathrm{ml}$ ) and incubate for $2 \mathrm{~h}$ before radiation. After exposure to ionizing radiation, the culture medium was carefully removed and exchanged for a fresh medium and cells were incubated for $6 \mathrm{~h}$ in a humidified atmosphere of $5 \% \mathrm{CO}_{2}$ in air at $37^{\circ} \mathrm{C}$. After that, culture medium was carefully removed and washed with $1 \mathrm{ml}$ cold PBS and remove it, then added $\mathrm{Na}$ citrate $/ \mathrm{KCl}$ and incubated for 10 min. Cells were fixed with $1 \%$ glutaraldehyde/PBS and treated with $40 \mu \mathrm{g} / \mathrm{ml}$ propidium iodide (PI) for $15 \mathrm{~min}$ in the dark. Apoptotic cells with morphological changes such as fragmentation and condensation of chromatin were counted in atleast 500 cells (Inanami et al., 2004). Normal and apoptotic cells were examined using a Nikon eclipse 50i microscope (Japan) with reflected-light fluorescence (Figure 2). A typical photomicrograph of normal (A) and apoptosis cell (B and C) is shown in Figure 2.

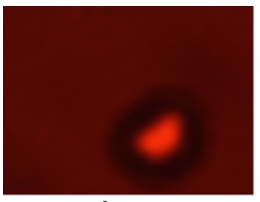

A

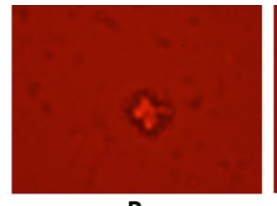

B

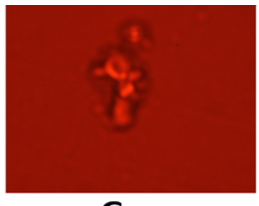

C
Figure 2. Typical photomicrograph of Normal (A) and Apoptosis cell (B and C) in Fluorescence Microscopic at $40 x$

\section{Statistical analysis}

All data are presented as mean \pm SD from at least three separate experiments. The statistical analyses were performed using Microsoft excel software. All P-values $<0.05$ were considered to represent significant differences. Student t-test was used in this study.

\section{Results}

\section{PLC analysis}

For characterization of thymol using HPLC, we used different solvents as mobile phase in HPLC (methanol, acetic acid, water and acetonitrile). Finally the mobile phase was selected an isocratic combination of acetonitrile: $\mathrm{H}_{2} \mathrm{O}$ : acetic acid $(65: 34: 1)$ at flow rate 1 $\mathrm{ml} / \mathrm{min}$. Analysis was performed at ambient temperature. In this mobile phase, the peaks of thymol and carvacrol were successfully separated in the samples and pure peak of thymol was reached for quantification. In $Z M$ extract, thymol and carvacrol had retention times 10.2 and 9.6 min, respectively (Figure 3).

Extract is Zataria multiflora that analyses with a mobile phase of acetonitrile: $\mathrm{H}_{2} \mathrm{O}$ : acetic acid (65:34:1). Different concentrations of thymol $(0.025,0.05,0.1,0.25$ and $0.5 \mathrm{mg} / \mathrm{ml}$ ) were prepared and injected to HPLC for calculation of peak area. Calibration graph was performed using the external standard technique following linear regression analysis by plotting concentration against peak area $\left(y=1744.5 x-3.2763, r^{2}=0.998\right)$. Thymol content was $6.0 \pm 0.11 \mathrm{mg} / \mathrm{g}$ in $Z M$ extract.

\section{Antiproliferation Assay}

Effects of $Z M$ on cell proliferation in glioblastoma and HFFF2 cells were determined by MTT assay. Glioblastoma cell proliferation was significantly inhibited by $Z M$ at concentration $200 \mu \mathrm{g} / \mathrm{ml}(\mathrm{p}<0.05)$. $Z M$ exhibited a reduction of $9 \%$ in cellular growth in glioblastoma cells when cells treated with $200 \mu \mathrm{g} / \mathrm{ml}$ of $Z M$ (Table 1).

Table1: Effect of $Z M$ at different concentrations (100 and $200 \mu \mathrm{g} / \mathrm{ml}$ ) on A172 cell line. Cell proliferation was assayed with MTT test. In the comparison of cancer cell, human non-malignant fibroblast cell (HFFF2) was used for any effect of $Z M$ on cell proliferation. $Z M$ did not cause significantly cellular toxicity in HFFF2 cell (Table 2).

Although IR alone in 3Gy and 6Gy induced cell death over $48 \mathrm{~h}$, IR in the presence of $Z M$ at

Table 1. Effect of ZM at Different Concentrations (100 and $200 \mu \mathrm{g} / \mathrm{ml}$ ) on A172 cell line. Cell Proliferation was Assayed with MTT Test

\begin{tabular}{lccc}
\hline Treatment & W/O IR $($ means \pm SD) & 3 Gy $($ means \pm SD) & 6 Gy $($ means \pm SD) \\
\hline cell & $100.28 \pm 7.49$ & $91.79 \pm 6.81$ & $76.35 \pm 5.09$ \\
control & $100.05 \pm 4.74$ & $91.66 \pm 7.27$ & $75.10 \pm 7.10$ \\
Z25 & $99.90 \pm 9.57$ & $90.71 \pm 5.06$ & $74.81 \pm 7.11$ \\
Z50 & $95.83 \pm 9.56$ & $85.22 \pm 8.95$ & $73.95 \pm 4.45$ \\
Z100 & $97.84 \pm 7.22$ & $87.5 \pm 3.89$ & $73.67 \pm 7.10$ \\
Z150 & $95.54 \pm 8.13$ & $80.49 \pm 5.94 \mathrm{~b}$ & $73.10 \pm 6.44$ \\
Z200 & $91.76 \pm 8.57 \mathrm{a}$ & $76.04 \pm 4.27 \mathrm{c}$ & $66.19 \pm 8.42 \mathrm{~d}$ \\
\hline
\end{tabular}

*Values are given as mean \pm S.D. of three experiments in each group. a $\mathrm{p}<0.05$, comparison ZM 200 with control in group without radiation, $\mathrm{b}$ $\mathrm{p}<0.05$, comparison ZM 150 with control in group irradiated 3 Gy. c p $<0.05$, comparison ZM 200 with control in group irradiated 3 Gy.d p $<0.05$, comparison ZM 200 with control in group irradiated 6Gy 
Table 2. Effect of ZM at Different Concentrations (100 and $200 \mu \mathrm{g} / \mathrm{ml}$ ) on HFFF2 Cell Line. Cell Proliferation was Assayed with MTT Test

\begin{tabular}{lccc}
\hline Treatment group & W/O IR(means $\pm \mathrm{SD})$ & 3 Gy(means $\pm \mathrm{SD})$ & $6 \mathrm{~Gy}(\mathrm{means} \pm \mathrm{SD})$ \\
\hline cell & $100.22 \pm 6.20$ & $92.93 \pm 7.34$ & $83.56 \pm 5.70$ \\
control & $101.02 \pm 9.36$ & $92.97 \pm 4.90$ & $82.31 \pm 7.33$ \\
Z25 & $100.22 \pm 3.42$ & $96.73 \pm 1.89$ & $84.02 \pm 3.75$ \\
Z50 & $102.72 \pm 8.65$ & $94.55 \pm 3.12$ & $85.28 \pm 6.99$ \\
Z100 & $108.29 \pm 7.31$ & $94.78 \pm 5.93$ & $83.56 \pm 2.67$ \\
Z150 & $102.83 \pm 7.47$ & $92.65 \pm 6.29$ & $83.72 \pm 4.58$ \\
Z200 & $97.41 \pm 5.46$ & $88.43 \pm 4.83$ & $81.95 \pm 6.96$ \\
\hline
\end{tabular}

*Values are given as mean \pm S.D. of three experiments in each group. There are not any $\mathrm{p}<0.05$, comparison each concentration of ZM with control in each group
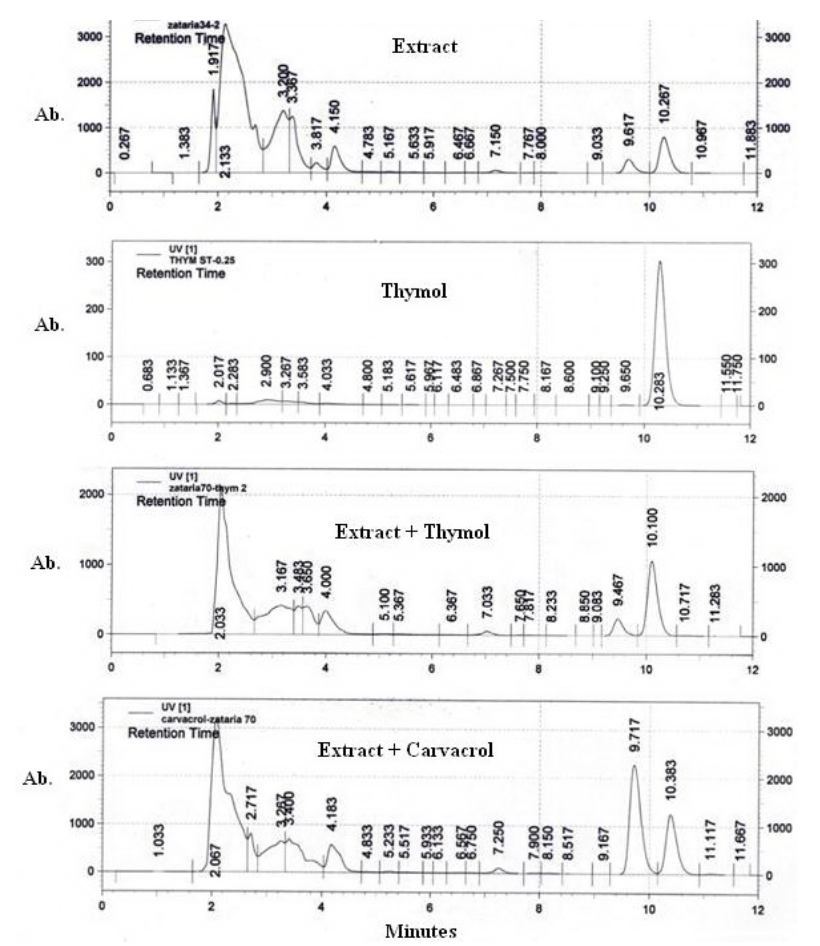

Figure 3. HPLC Chromatograms of Extract, Thymol, Extract + Thymol and Extract + Carvacrol. Extract is Zataria Multiflora that analyses with a mobile phase of acetonitrile: $\mathrm{H}_{2} \mathrm{O}$ : acetic acid (65:34:1)

dose of $150 \mu \mathrm{g} / \mathrm{ml}$ and $200 \mu \mathrm{g} / \mathrm{ml}$ in 3Gy and $200 \mu \mathrm{g} /$ $\mathrm{ml}$ in 6Gy significantly decreased cell viability in A172 cells $(\mathrm{p}<0.05) . Z M$ exhibited a reduction $24 \%$ and $34 \%$ when cells treated with $200 \mu \mathrm{g} / \mathrm{ml}$ of $Z M$ in $3 \mathrm{~Gy}$ and $6 \mathrm{~Gy}$, respectively, while this reduction was $10 \%$ and $24 \%$ in cellular growth in when cells irradiated at doses $3 \mathrm{~Gy}$ and 6Gy alone, respectively (Table 1).

Despite, in HFFF2 cells, IR alone in 3Gy and 6Gy induced a limited cell death over $48 \mathrm{~h}$ but there are not any significant differences between cell viability by treatment of different doses of $Z M$ with IR (Table2).

Fluorescence microscopic observation of apoptotic cells

Radiation-induced apoptosis in A172 cells was significantly increased following treatment with $Z M$ at doses of $200 \mu \mathrm{g} / \mathrm{ml}$ (2.56\% in control vs. $5.08 \%$ in $Z M$, $\mathrm{p}<0.05)$ in $3 \mathrm{~Gy}$ and $(2.56 \%$ in control vs. $5.12 \%$ in $Z M$, $\mathrm{p}<0.05)$ in $6 \mathrm{~Gy} . Z M$ alone could increase apoptosis in A172 cells at doses of $200 \mu \mathrm{g} / \mathrm{ml}(2.56 \%$ in control vs.

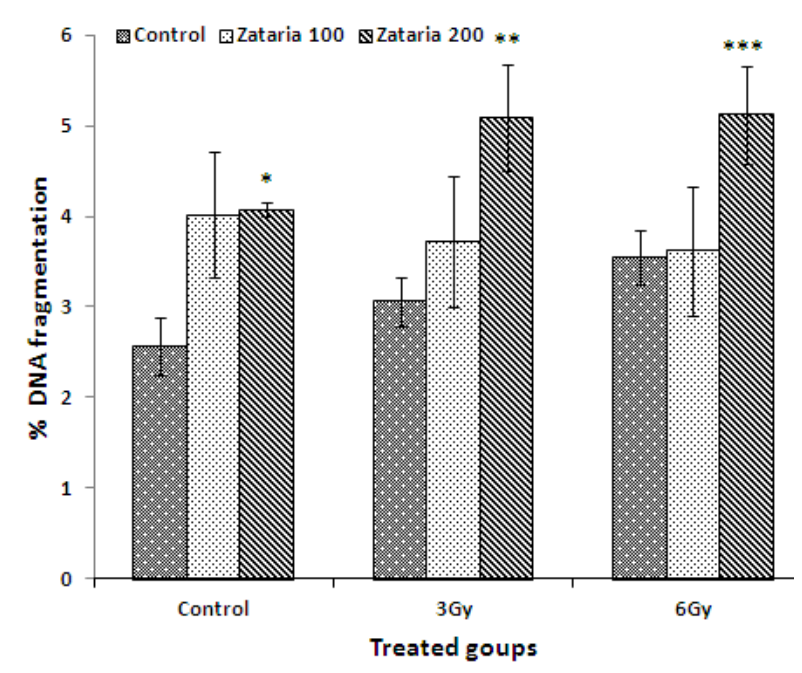

Figure 4. Effect of ZM at Different Concentrations (100 and $200 \mu \mathrm{g} / \mathrm{ml}$ ) on DNA Fragmentation in Cancer Cells (A172 Cell Line). Percentage of apoptotic cells was assayed with fluorescence microscopic. ${ }^{*} \mathrm{p}<0.05$, comparison ZM 200, with control in group without irradiation. ${ }^{*} \mathrm{p}<0.05$, comparison ZM 200, with control in group with irradiated 3G. $* * * p<0.05$, comparison ZM 200, with control in group with irradiated $6 \mathrm{G}$

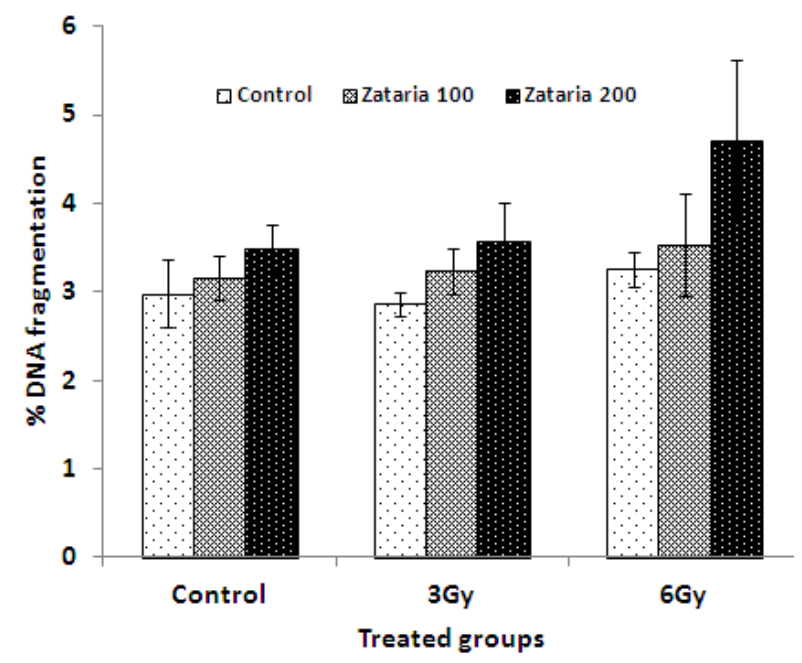

Figure 5. Effect of $\mathrm{ZM}$ at different concentrations (100 and $200 \mu \mathrm{g} / \mathrm{ml}$ ) on non-malignant cells (HFFF2 cell line). \% of Apoptotic cells was assayed with fluorescence microscopic. There are not any $\mathbf{p}<\mathbf{0 . 0 5}$, comparison each concentration of $\mathrm{ZM}$ with control in each group 
$4.07 \%, \mathrm{p}<0.05$ in $Z M$ ) (Figure 4).

Although $Z M$ induced a limited apoptosis in HFFF2 cells but there was not any significant apoptosis induction in HFFF2 cells at different doses of $Z M$ alone or with IR (Figure 5).

These data show that the radiosensitive effect of $Z M$ in A172 cells is due to the increase of radiation induced DNA fragmentation and a sub-lethal dose of $Z M$ efficiently sensitized cancer cells to IR.

\section{Discussion}

In this study, the combination effects of $Z M$ and radiation on the percentage of cell proliferation and DNA fragmentation in control, ZM-pretreated, and/or radiation treated A172 and HFFF2 cells were studied. RT plays a key role in the local treatment of solid tumors by inducing DNA damage, triggering cell cycle arrest and apoptosis. The therapeutic effect of IR in cancer patients depends on tumor radiosensitivity and the tolerance of normal tissues. (Park et al., 2014) According the result of our study, ZM exhibited a radiosensitive effect on glioblastoma cells and exhibited a synergistic effect on cell killing by ionizing radiation on cancer cells. It was not observed any statistically significant difference in nonmalignant HFFF2 cells growth in $Z M$ alone and with radiation. It seems that $Z M$ has a radiosensitive effect on cancer cell and radioprotective effect on normal cell. The biological effects of $Z M$ are mainly phenolic compounds, especially thymol and carvacrol. (Mahboubi and Bidgoli, 2010) Our results agree with those of others who showed that thymol and carvacrol has an essential in vitro anti-neoplasm effect against cancer cells. (Jaafari et al., 2009)

In this study radiation-induced apoptosis in A172 cells was significantly increased following treatment with $Z M$ at concentration of $200 \mu \mathrm{l} / \mathrm{ml}$. It was not observed any enhanced apoptosis in HFFF2 cells treated with $Z M$ and exposed to ionizing radiation. This result agrees with our previous study showed that $Z M$ with antioxidant properties can probably contribute to reduce the genotoxicity induced by irradiation in normal cells of human lymphocytes. The result of our previous study showed that $Z M$ extract reduced the frequency of microuclei in binucleated lymphocytes that were affected by ionizing irradiation and can act as a radioptotector for human normal cells. Antioxidant property was proposed the main mechanism action of $Z M$ extract for radioprotection. (Hosseinimehr et al., 2011). $Z M$ recognized with important medicinal activities including anti oxidative stress (Sharififar et al., 2007; Kavoosi et al., 2012), antimicrobial (Alizadeh et al., 2009; Mahboubi and Bidgoli, 2010), anti-inflammatory (Sajed et al., 2013) and radioprotective. (Hosseinimehr et al., 2011) The cytoprotective and antimutagenic effects of thymol has been extensively reported. Anyway, some studies also have indicated the antitumor activity of thymol. (Karkabounasli et al., 2006; Jaafari et al., 2009). Thymol caused activation of caspase- 9 and -3 concomitant PARP cleavage and it induced disruption of mitochondrial membrane potential, which is associated with caspasedependent apoptosis. (Fang and $\mathrm{Ng}, 2013$ ). The result of Jaafari, et al study showed that carvacrol and thymol have an important in vitro antitumor effect against tumor cells and these compounds revealed a sub-G1 peak and it is an indicator of the onset of apoptosis. (Jaafari et al., 2009) Recent studies reported that combination of thymol and carvacrol had a synergistic antioxidant and anti-inflammatory effects on rats treated by cisplatin. (El-Sayed et al., 2015)

Our results show that $Z M$ has a synergistic effect with irradiation on cancer cell growth inhibition; it is related to the radiosensitive effect of $Z M$ on cancer cells.

Interestingly, $Z M$ at all doses did not show any enhancement of toxicity on HFFF2 cells alone or in combination with irradiation. These results are promising for using this natural product in combination with radiotherapy in patients.

Conclusion: This study shows that the Zataria multiflora has a selective radiosensitive effect onglioblastoma cell through the increasing of radiation-induced apoptosis as well as anti-proliferation effect. It can use as a herbal medicine for improvement of efficacy of ionizing radiation in patients during radiotherapy.

\section{Acknowledgements}

This study was supported by a grant from Mazandaran University of Medical Sciences, Sari, Iran. This research was the subject of a PhD thesis of Azar Aghamohammadi as a student of Mazandaran University of Medical Sciences

\section{References}

Alizadeh NS, Khoei EM, Fazelimanesh M, et al (2009). Antibacterial effects of Zataria multiflora boiss (shirazi avishan extract) on urinary tract escherichia coli infections. Res J Biological Sci, 4, 891-4.

Amanlou M, Beitollahi JM, Abdollahzadeh S, et al (2006). Miconazole gel compared with Zataria multiflora Boiss. gel in the treatment of denture stomatitis. Phytother Res, 20, 966-9.

Antoccia A, Sgura A, Berardinelli F, et al (2009). Cell cycle perturbations and genotoxic effects in human primary fibroblasts induced by low-energy protons and $\mathrm{X} / \gamma$-rays. $J$ Radiat Res, 50, 457-68.

Baskar R, Lee KA, Yeo R, et al (2012). Cancer and radiation therapy: current advances and future directions. Int $\mathrm{J}$ Med Sci, 9, 193-9.

Chakravarti A, Palanichamy K (2008). Overcoming therapeutic resistance in malignant gliomas: current practices and future directions. Cancer Treat Res, 139, 173-89

El-Sayed EM, Abd-Allah AR, Mansour AM, El-Arabey AA (2015). Thymol and carvacrol prevent cisplatininduced nephrotoxicity by abrogation of oxidative stress, inflammation, and apoptosis in rats. J Biochem Mol Toxicol, 29, 165-72.

Fang EF, Ng TB (2013). Antitumor potential and other emerging medicinal properties of natural compounds, springer.

Hosseinimehr SJ, Mahmoudzadeh A, Ahmadi A, et al (2011). The radioprotective effect of Zataria multiflora against genotoxicity induced by $\gamma$ irradiation in human blood lymphocytes. Cancer Biother Radiopharm, 26, 325-9.

Hosseinzadeh H, Ramezani M, Salmani G (2000). Antinociceptive, anti-inflammatory and acute toxicity effects of Zataria multiflora Boiss extracts in mice and rats. J Ethnopharmacol, 73, 379-85. 
Azar Aghamohamamdi et al

Jaafari A, Mouse H, M'Bark L, et al (2009). Differential antitumor effect of essential oils and their major components of Thymus broussonettii: relationship to cell cycle and apoptosis induction. Herba Polonica, 55, 36-50.

Jaffary F, Ghannadi A, Siahpoush A (2004). Antinociceptive effects of hydroalcoholic extract and essential oil of Zataria multiflora. Fitoterapia, 75, 217-20.

Karkabounasli S, Metsios A, Lekkas P, et al (2006). Anticarcinogenic and antiplatelet effects of carvacrol. Expe Oncol, 28, 121-5.

Kavoosi G, Teixeira da Silva JA, Saharkhiz MJ (2012). Inhibitory effects of Zataria multiflora essential oil and its main components on nitric oxide and hydrogen peroxide production in lipopolysaccharide-stimulated macrophages. J Pharm Pharmacol, 64, 1491-500.

Kma L (2014). Plant extracts and plant-derived compounds: promising players in a countermeasure strategy against radiological exposure. Asian Pac J Cancer Prev, 15, 240525.

Lachumy SJ, Oon CE, Deivanai S, et al (2013). Herbal remedies for combating irradiation: a green anti-irradiation approach. Asian Pac J Cancer Prev, 14, 5553-65.

Mahboubi M, Bidgoli FG (2010). Antistaphylococcal activity of Zataria multiflora essential oil and its synergy with vancomycin. Phytomedicine, 17, 548-50.

Maurya DK, Devasagayam TP, Nair CKK (2006). Some novel approaches for radioprotection and the beneficial effect of natural products. Indian J Exp Biol, 44, 93-114.

Park SS, Kim YJ, Ju EJ, et al (2014). Ibulocydine sensitizes human cancers to radiotherapy by induction of mitochondriamediated apoptosis. Radiother Oncol, 112, 295-301.

Ramezani M, Hosseinzadeh H, Samizadeh S (2004). Antinociceptive effects of Zataria multiflora Boiss fractions in mice. J Ethnopharmacol, 91, 167-70.

Saei-Dehkordi SS, Tajik H, Moradi M, et al (2010). Chemical composition of essential oils in Zataria multiflora boiss. from different parts of Iran and their radical scavenging and antimicrobial activity. Food Chem Toxicol, 48, 1562-7.

Sajed H, Sahebkar A, Iranshahi M (2013). Zataria multiflora Boiss. shirazi thyme-an ancient condiment with modern pharmaceutical uses. J Ethnopharmacol, 145, 686-98.

Sebastia N, Almonacid M, Villaescusa JI, et al (2013). Radioprotective activity and cytogenetic effect of resveratrol in human lymphocytes: an in vitro evaluation. Food Cheml Toxicol, 51, 391-5.

Sharififar F, Moshafi M, Mansouri S, et al (2007). In vitro evaluation of antibacterial and antioxidant activities of the essential oil and methanol extract of endemic Zataria multiflora Boiss. Food Control, 18, 800-5.

Shokri H, Asadi F, Bahonar AR, et al (2006). The role of Zataria multiflora essence (Iranian herb) on innate immunity of animal model. Iran J Immunol, 3, 164-8.

Szostak MJ, Kyprianou N (2000). Radiation-induced apoptosis: predictive and therapeutic significance in radiotherapy of prostate cancer (review). Oncol Rep, 7, 699-706.

Vogelstein B, Kinzler KW (2004). Cancer genes and the pathways they control. Nat Med, 10, 789-99.

Wang K, Liu C, Di CJ, et al (2014). Kojic acid protects C57BL/6 mice from gamma-irradiation induced damage. Asian Pac J Cancer Prev, 15, 291-7.

Xu P, Zhang WB, Cai XH, et al (2014). Flavonoids of Rosa roxburghii Tratt act as radioprotectors. Asian Pac J Cancer Prev, 15, 8171-5.

Yao JX, Yao ZF, Li ZF, et al (2014). Radio-sensitization by Piper longumine of human breast adenoma MDA-MB-231 cells in vitro. Asian Pac J Cancer Prev, 15, 3211-7.

Yao KC, Komata T, Kondo Y, et al (2003). Molecular response of human glioblastoma multiforme cells to ionizing radiation: cell cycle arrest, modulation of cyclin-dependent kinase inhibitors, and autophagy. J Neurosurg, 98, 378-84. 